\title{
Evaluation of simplified acute physiology score 3 performance: a systematic review of external validation studies
}

\author{
Antonio Paulo Nassar Junior ${ }^{1 *}$, Luiz Marcelo Sa Malbouisson ${ }^{1}$ and Rui Moreno ${ }^{2}$
}

\begin{abstract}
Introduction: Simplified Acute Physiology Score 3 (SAPS 3) was the first critical care prognostic model developed from worldwide data. We aimed to systematically review studies that assessed the prognostic performance of SAPS 3 general and customized models for predicting hospital mortality in adult patients admitted to the ICU.

Methods: Medline, Lilacs, Scielo and Google Scholar were searched to identify studies which assessed calibration and discrimination of general and customized SAPS 3 equations. Additionally, we decided to evaluate the correlation between trial size (number of included patients) and the Hosmer-Lemeshow (H-L) statistics value of the SAPS 3 models.

Results: A total of 28 studies were included. Of these, 11 studies (42.8\%) did not find statistically significant mis-calibration for the SAPS 3 general equation. There was a positive correlation between number of included patients and higher $\mathrm{H}-\mathrm{L}$ statistics, that is, a statistically significant mis-calibration of the model $(r=0.747, P<0.001)$. Customized equations for major geographic regions did not have statistically significant departures from perfect calibration in 9 of 19 studies. Five studies (17.9\%) developed a regional customization and in all of them this new model was not statistically different from a perfect calibration for their populations. Discrimination was at least very good in 24 studies (85.7\%).

Conclusions: Statistically significant departure from perfect calibration for the SAPS 3 general equation was common in validation studies and was correlated with larger studies, as should be expected, since $\mathrm{H}$-L statistics (both $\mathrm{C}$ and $\mathrm{H}$ ) are strongly dependent on sample size This finding was also present when major geographic customized equations were evaluated. Local customizations, on the other hand, improved SAPS 3 calibration. Discrimination was almost always very good or excellent, which gives excellent perspectives for local customization when a precise local estimate is needed.
\end{abstract}

\section{Introduction}

Prognostic models are important tools in critical care medicine [1]. They are used for mortality predictions and for illness severity assessment in clinical trials. Acute physiology and chronic health evaluation II (APACHE II) [2] and simplified acute physiology score II (SAPS II) [3] are the most commonly used models worldwide. Although they are still able to assess severity in clinical trials, their usefulness for mortality predictions has been questioned due to a lack of prognostic performance over time, since they were developed more than 20 years ago. This limitation is very important because observed-to-expected mortality ratios have become standard to assess the impact of ICU factors on outcome and are among the

\footnotetext{
*Correspondence: paulo_nassar@yahoo.com.br

${ }^{1}$ Anesthesiology Department, Hospital das Clinicas SP-FMUSP, Av. Dr. Enéas de Carvalho Aguiar, 255, Cerqueira César, São Paulo, SP 05403-000, Brazil Full list of author information is available at the end of the article
}

safety and quality indicators that an ICU should apply to evaluate quality of care [4].

In 2002, a worldwide group of researchers collected new data about physiologic alterations, clinical presentation and outcome of critically ill patients in more than 300 ICUs worldwide [5]. These data led to the development of a new prognostic model, the SAPS III [6]. For the first time, a general outcome prediction model included data from outside Europe or the USA. Besides the general equation for mortality estimation, SAPS III also provided the end-user with customized equations for seven different regions of the world, which would theoretically improve care quality evaluations and benchmarking.

Since then, SAPS III models have been prospectively evaluated for their performance in several regional studies. Our aim was to systematically review studies that assessed the prognostic performance of SAPS III general and 
customized models for predicting hospital mortality in adult patients admitted to ICU. Specifically, we aimed to review how SAPS III calibrated and discriminated in external validation studies.

\section{Methods}

Search strategy

Medline, Lilacs (Literatura Latino-Americana e do Caribe em Ciências da Saúde) and Scielo (Scientific Electronic Library Online) were searched for articles published from 1 January 2005 (because the original SAPS III description was published in that year) to 1 October 2013 using the term 'simplified acute physiology score'. Besides that, Google Scholar was searched for articles that cited the original SAPS III publication [6]. Titles and abstracts returned by the search strategy were analyzed for eligibility and full-text copies of articles deemed to be potentially relevant were retrieved. Duplicate publications were excluded, as well as studies published only as abstracts and editorials, letters and narrative reviews. Only articles published in English, Portuguese, Spanish or French were included. Eligibility assessment was performed independently in an unblinded standardized manner by two reviewers (APNJ and LMSM). Disagreements were resolved by consensus. The preferred reporting items for systematic reviews and meta-analyses (PRISMA) statement was used for guidance [7]. This study did not need ethical approval nor was individual patient consent needed as only data from published studies were used.

\section{Study selection}

One of the criteria used to include studies in this review was whether they assessed the general SAPS III equation performance on predicting hospital mortality in an adult population ( $\geq 16$ years-old) admitted to an ICU. Included studies needed to have evaluated at least both calibration and discrimination of the model. Calibration refers to whether the predicted probabilities of death in the hospital agree with the observed ones. Discrimination refers to the ability of the model to distinguish high-risk subjects from low-risk subjects. When reported in the included studies, calibration and discrimination data from customized SAPS III equations for major areas of the world were also reported here.

We decided to include only studies that used data collected after 2002, when data for original SAPS III were available $[5,6]$. This decision was made in order to avoid conclusions about performance of the model based on a different profile of treatments administered in a previous period of time.

\section{Quality assessment}

Included studies were evaluated for quality according to the following items, based on a guideline for systematic review of prognostic studies [8]: 1) study participation: study population was clearly defined and described; 2) prognostic factor measurement: SAPS III was properly measured (that is, data were collected as described on the original study); 3) analysis: adequate description of the test methods for discrimination and calibration and sufficient presentation of data to assess adequacy of analysis.

\section{Data extraction}

We developed a data extraction sheet. One author (APNJ) extracted the following data from included studies: number of patients, mean or median age, percentage of female patients and percentage of patients admitted for a surgical reason (defined as ICU admission from the operating room when not explicitly stated). The second author (LMSM) checked the extracted data. Authors of the included studies were contacted by email to complete the missing data that were required for characterizing the studies. When the authors could not be contacted, did not reply or their answer was still unclear, empty fields were marked 'Not Reported (NR)'.

For each included study, we described the reported calibration and discrimination. Calibration is usually measured by the Hosmer-Lemeshow (H-L) goodness-of-fit $\mathrm{H}$ - or $\mathrm{C}$-statistics. These statistics test for significant departures from perfect calibration when $P$-values are greater than 0.05 . The $H$-statistic is based on fixed cut points on the predictions (for example, deciles of risk) whereas the $C$-statistic is based on equally sized groups, based on probability of death. Additionally, calibration may be evaluated by the Cox test of calibration. In this case, logistic regression is used to verify the agreement between predicted and observed risks.

In studies in which both the general and the customized SAPS III showed significant departure from perfect calibration, we assessed if authors performed a customization and if this new model was an adequate calibration for the study population. First-level customization is performed using logistic regression analysis by computing a new logistic coefficient while maintaining the same variables with the same weights as the original model [9].

Discrimination is assessed measuring the area under the receiver operator characteristic (aROC) curve. aROC and its 95\% CI were calculated. Discrimination was considered excellent, very good, good, moderate or poor with aROC values of 0.9 to $0.99,0.8$ to $0.89,0.7$ to 0.79 , 0.6 to 0.69 and $\leq 0.6$, respectively. When available, we also presented the standardized mortality ratio (SMR) for hospital mortality reported in the studies. SMR is calculated by dividing observed hospital mortality by the predicted hospital mortality.

As classical calibration tests (such as H-L statistics) are extremely sensitive to sample size $[10,11]$, we decided to evaluate if there was a correlation between sample size 
and calibration tests. Spearmann correlation coefficient was calculated between the number of included patients and the value of $\mathrm{H}-\mathrm{L}$ statistics found. For studies presenting both the $\mathrm{H}$ - and $\mathrm{C}$-statistic, we choose the one that reported the lower value. Analysis was performed on SPSS version 22.0 (SPSS Inc.).

\section{Results}

\section{Study characteristics}

Out of 923 studies initially identified, 31 full-text articles were assessed for eligibility. Two were excluded for not performing any measure of calibration $[12,13]$ and one for using data collected before 2002 [14]. Twenty-eight studies were included in this analysis (Figure 1).

Table 1 shows the characteristics of the included studies. According to major geographic regions defined in the original SAPS III study, there were ten studies (35.7\%) performed in Central and South America [15-24], one (3.6\%) in North America [25], eight (34.8\%) in Australasia [26-33], three (10.7\%) in Central and Western Europe [34-36], two (7.1\%) in Northern Europe [37,38] and four (14.3\%) in Southern Europe and Mediterranean countries [39-42]. Most studies (53.5\%) were performed in a single ICU. Included studies examined the total number of 63,261 patients, ranging from 95 to 28,357 .

Although most studies aimed to validate SAPS III on a broad population in medical, surgical or mixed ICUs, nine studies (32.1\%) applied SAPS III to patients with specific conditions such as cancer [15,20], elderly [17], acute kidney injury (AKI) [18,21,31], acute coronary syndromes [23], septic shock [30] and transplant patients [24].

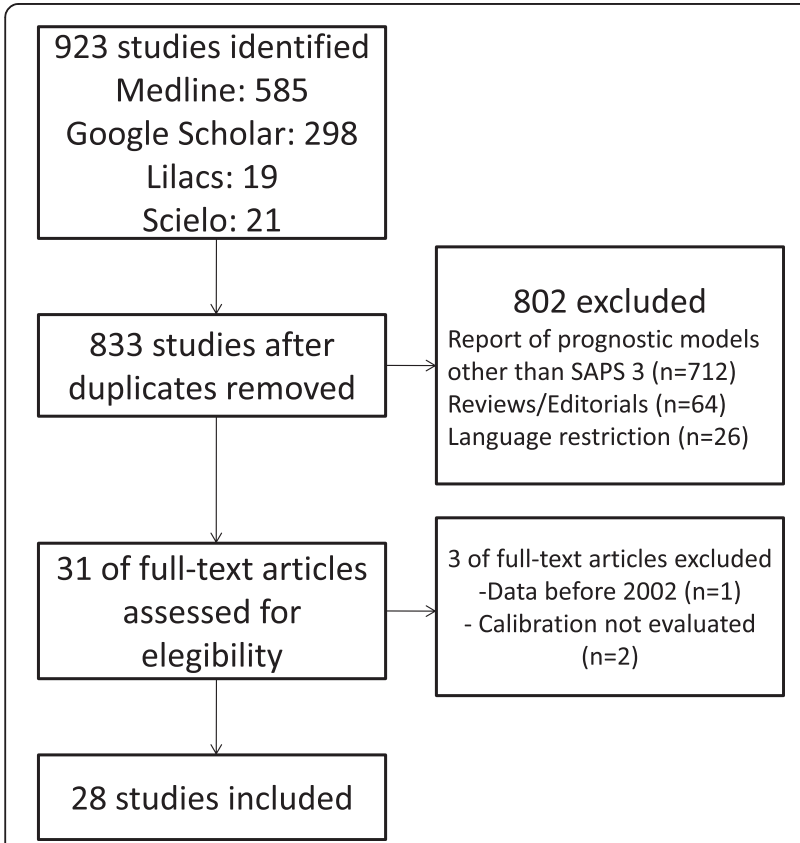

Figure 1 Search strategy. SAPS, simplified acute physiology score.
Khwannimit et al. performed three studies in the same ICU and enrolled some patients in more than one study $[27,28,30]$. Lim et al. included 4,617 patients, but the SAPS III general equation was only assessed on 2,309 patients, a 'development cohort' in which a customized Korean SAPS III was generated [33]. The Australasian SAPS III equation was assessed in the entire population, but we only extracted data from the development cohort for comparison with SAPS III general equation data on calibration and SMR.

\section{Study quality}

Study quality assessment is shown in Table 2. Three studies did not calculate SAPS III with data collected within one hour from admission. Tsai et al. aimed to validate SAPS III at dialysis commencement in a population supported by extracorporeal membrane oxygenation [31]. Although they also calculated SAPS III at ICU admission, they only evaluated discrimination at this point. Maccariello et al. applied SAPS III in an AKI population at the start of renal replacement therapy [18]. Costa e Silva et al. also studied an AKI population and applied SAPS III on AKI diagnosis and on nephrology consultation day, using data collected during the previous 24 hours [21].

\section{Calibration and discrimination}

Only one study opted for the Cox calibration test instead of $\mathrm{H}-\mathrm{L}$ statistics to assess calibration [41]. A non-significant departure from the perfect calibration was found in eleven studies (42.8\%) (Table 3) [15,16,18,19,21,29,31,32,37,38,40].

A positive correlation was found between sample size and the value of $\mathrm{H}-\mathrm{L}$ statistics in the 27 studies that used it to assess calibration $(r=0.747 ; P<0.001)$, meaning that larger studies correlated with higher $\mathrm{H}$-L values representing greater power to detect mis-calibration.

Nineteen studies (67.9\%) also assessed calibration for the customized SAPS III equation for their major geographic region (Table 3) $[15,17,18,20,21,24,26,27,32-37,39-42]$. A non-significant departure from perfect calibration was found in six studies, in which the general equation also did not show a statistically significant mis-calibration $[15,18,21,32,37,40]$. Three studies $[20,26,34]$, did not show a significant departure from perfect calibration for SAPS III customized equations, unlike the general SAPS III equation, which was statistically significantly mis-calibrated in those studies. In all remaining 10 studies, significant departures from perfect calibration were found for both customized and general equations $[17,24,27,28,32,33,35,36,39,41,42]$.

Five studies (17.9\%), in which both general SAPS III equation and major geographic customized equations were statistically significantly different from perfect calibration, performed a regional customization. All studies developed 
Table 1 Study characteristics

\begin{tabular}{|c|c|c|c|c|c|c|c|}
\hline Study & Setting & Study period & $\begin{array}{l}\text { Number of } \\
\text { patients }\end{array}$ & Age (years) & Female (\%) & $\begin{array}{l}\text { Surgical } \\
\text { admission (\%) }\end{array}$ & $\begin{array}{l}\text { Hospital } \\
\text { mortality (\%) }\end{array}$ \\
\hline Soares, 2006 [15] & $1 \mathrm{ICU}$, Brazil & Jan 2003 to Dec 2005 & 952 & Mean: 58.3 & 45.3 & 63.5 & 33.5 \\
\hline Serrato, 2007 [16] & $1 \mathrm{ICU}$, Mexico & Jan 2006 to May 2006 & 95 & Mean: 59 & 49.0 & 28.0 & 20.0 \\
\hline Ledoux, 2008 [34] & $1 \mathrm{ICU}$, Belgium & Dec 2005 to Jul 2006 & 802 & Median: 66 & 39.4 & 71.1 & 17.5 \\
\hline Duke, 2008 [26] & $1 \mathrm{ICU}$, Australia & Oct 2005 to Dec 2007 & 1,741 & Median: 66 & 47.4 & 39.4 & 11.3 \\
\hline Tsai, 2008 [31] & $1 \mathrm{ICU}$, Taiwan & Jan 2002 to Dec 2006 & 104 & Mean: 51 & 42.3 & 61.4 & 76 \\
\hline Sakr, 2008 [35] & $1 \mathrm{ICU}$, Germany & Aug 2004 to Dec 2005 & 1,851 & Mean: 61.6 & 36.6 & 85.8 & 9.0 \\
\hline Metnitz, 2009 [36] & $22 \mathrm{ICU}$, Austria & Oct 2006 to Feb 2007 & 2,060 & Mean: 64.9 & 42.0 & 57.5 & 21.7 \\
\hline Capuzzo, 2009 [39] & 2 ICU, Italy & Jan 2006 to Sep 2007 & 684 & Median: 73 & 37.0 & 81.8 & 19.6 \\
\hline Strand, 2009 [37] & 2 ICU, Norway & Jun 2006 to Dec 2007 & 1,862 & Median: 63 & 36.0 & 29.4 & 23.6 \\
\hline Alves, 2009 [17] & 1 ICU, Brazil & Jan 2006 to Dec 2006 & 350 & Mean: $73.4^{a}$ & 48.0 & 31.1 & 30.6 \\
\hline Mbongo, 2009 [40] & $1 \mathrm{ICU}$, Spain & Jan 2006 to Dec 2006 & 864 & Mean: 60.7 & 34.7 & 86.3 & 8.2 \\
\hline \multirow[t]{2}{*}{ Poole, 2009 [41] } & 147 ICU, Italy & Feb 2007 to Dec 2007 & 28,357 & Mean: 65.8 & 40.7 & 53.5 & 29.6 \\
\hline & & & & Median: 70 & & & \\
\hline Maccariello, 2010 [18] & 11 ICU, Brazil & Jan 2007 to Jul 2008 & 244 & Mean: 69.5 & 43.0 & 19.0 & 68.0 \\
\hline Silva Junior, 2010 [19] & 2 ICU, Brazil & Mar 2008 to Mar 2009 & 1,310 & Mean: 67.1 & 60.5 & 100 & 10.8 \\
\hline Khwannimit, 2010 [27] & $1 \mathrm{ICU}$, Thailand & Jan 2005 to Dec 2010 & 1,873 & Median: 62 & 41.1 & 0 & 28.6 \\
\hline Soares, 2010 [20] & 28 ICU, Brazil & Aug 2007 to Sep 2009 & 717 & Mean: 61.2 & 51.0 & 64.0 & 30.0 \\
\hline Khwannimit, 2011 [28] & $1 \mathrm{ICU}$, Thailand & Mar 2007 to Aug 2009 & 2,022 & Median: 62 & 40.0 & 0 & 26.1 \\
\hline Lim, 2011 [32] & $1 \mathrm{ICU}$, South Korea & Mar 2008 to Feb 2009 & 633 & Mean: 60 & 37.0 & 0 & 31.0 \\
\hline Costa e Silva, 2011 [21] & 6 ICU, Brazil & Nov 2003 to Jun 2005 & 366 & Mean: 57.1 & 41.0 & 23.5 & 67.8 \\
\hline Christensen, 2011 [38] & $1 \mathrm{ICU}$, Denmark & Jan 2007 to Dec 2007 & 469 & NR & 66.3 & 63.5 & 17.7 \\
\hline Juneja, 2012 [29] & $1 \mathrm{ICU}$, India & Jul 2008 to Sep 2009 & 653 & Mean: 58.5 & 42.1 & 0 & 15.8 \\
\hline Nassar Junior, 2012 [22] & 3 ICU, Brazil & Jul 2008 to Dec 2009 & 5,780 & Median: 66 & 52.7 & 20.9 & 9.1 \\
\hline Keegan, 2012 [25] & $3 \mathrm{ICU}$, USA & Jan 2006 to Dec 2006 & 2,596 & Mean: 63.2 & 45.2 & 19.8 & 10.9 \\
\hline Nassar Junior, 2013 [23] & 3 ICU, Brazil & Jul 2008 to Dec 2009 & 1,015 & Median: 61 & 40.4 & 0 & 2.1 \\
\hline De Oliveira, 2013 [24] & 1 ICU, Brazil & May 2006 to Jan 2007 & 501 & Mean: 46 & 34.5 & 100 & 7.8 \\
\hline Khwannimit, 2013 [30] & $1 \mathrm{ICU}$, Thailand & Jan 2005 to Dec 2010 & 880 & Median: 59 & 42.4 & 30.6 & 57.4 \\
\hline Lim, 2013 [33] & $22 \mathrm{ICU}$, South Korea & Jul 2010 to Jan 2011 & $2,309^{b}$ & Median: 62 & 35.3 & 39.8 & 20.1 \\
\hline López-Caler, 2013 [42] & $6 \mathrm{ICU}$, Spain & Jan 2006 to Oct 2007 & 2,171 & Mean: 61.4 & NR & 37.2 & 16.0 \\
\hline
\end{tabular}

${ }^{\mathrm{a}}$ Only patients aged $\geq 60$ years were included; ${ }^{\mathrm{b}}$ development cohort in which a customized SAPS III equation was developed. NR, not reported.

a model which then did not show a statistically significant departure from perfect calibration for their populations $[27,28,33,35,36]$. Only two of these studies were multicenter $[33,36]$.

Discrimination was always very good (aROC 0.80 to 0.89 ) or excellent (aROC $\geq 0.90$ ) in 24 studies $(85.7 \%)$ [15-23,25-30,33-37,39-42]. None of the studies showed poor discrimination (Table 3 ).

\section{Mortality prediction}

Twenty-five studies (89.3\%) reported SMR for hospital mortality [15-30,32-34,36,37,39-42]. The SAPS III general equation underestimated hospital mortality in six studies (24\%) $[15,18-21,24]$ and overestimated it in $15(60 \%)$ $[22,23,25-29,33,34,36,37,39-42]$. Two studies (8\%) reported an SMR lower than 1 but did not report the 95\% CI [16,32] (Table 3).

Out of the 19 studies that assessed the customized SAPS III equation for their major geographic region, the customized SAPS III still overestimated hospital mortality in 10 studies (52.6\%) [27,28,32-34,36,37,39-41]. In one study, the customized SAPS III also underestimated hospital mortality [24]. However, in six studies, switching from the general to the customized equation was associated with better mortality estimation $[15,18,20,21,26,34]$ (Table 3 ).

\section{Discussion}

This systematic review of literature identified 28 studies that addressed SAPS III performance in external populations. As SAPS III enrolled patients from diverse countries, 
Table 2 Quality assessment of included studies

\begin{tabular}{|c|c|c|c|}
\hline Study & $\begin{array}{l}\text { Study } \\
\text { participation }\end{array}$ & $\begin{array}{l}\text { Prognostic factor } \\
\text { measurement }\end{array}$ & Analysis \\
\hline Soares, 2006 [15] & Yes & Yes & Yes \\
\hline Serrato, 2007 [16] & Yes & Yes & Yes \\
\hline Ledoux, 2008 [34] & Yes & Yes & Yes \\
\hline Duke, 2008 [26] & Yes & Yes & Yes \\
\hline Tsai, 2008 [31] & Yes & No & Yes \\
\hline Sakr, 2008 [35] & Yes & Yes & Yes \\
\hline Metnitz, 2009 [36] & Yes & Yes & Yes \\
\hline Capuzzo, 2009 [39] & Yes & Yes & Yes \\
\hline Strand, 2009 [37] & Yes & Yes & Yes \\
\hline Alves, 2009 [17] & Yes & Yes & Yes \\
\hline Mbongo, 2009 [40] & Yes & Yes & Yes \\
\hline Poole, 2009 [41] & Yes & Yes & Yes \\
\hline Maccariello, 2010 [18] & Yes & No & Yes \\
\hline Silva Junior, 2010 [19] & Yes & Yes & Yes \\
\hline Khwannimit, 2010 [27] & Yes & Yes & Yes \\
\hline Soares, 2010 [20] & Yes & Yes & Yes \\
\hline Khwannimit, 2011 [28] & Yes & Yes & Yes \\
\hline Lim, 2011 [32] & Yes & Yes & Yes \\
\hline Costa e Silva, 2011 [21] & Yes & No & Yes \\
\hline Christensen, 2011 [38] & Yes & NR & Yes \\
\hline Juneja, 2012 [29] & Yes & Yes & Yes \\
\hline Nassar Junior, 2012 [22] & Yes & Yes & Yes \\
\hline Keegan, 2012 [25] & Yes & Yes & Yes \\
\hline Nassar Junior, 2013 [23] & Yes & Yes & Yes \\
\hline De Oliveira, 2013 [24] & Yes & Yes & Yes \\
\hline Khwannimit, 2013 [30] & Yes & Yes & Yes \\
\hline Lim, 2013 [33] & Yes & Yes & Yes \\
\hline López-Caler, 2013 [42] & No & Yes & Yes \\
\hline
\end{tabular}

NR, not reported.

it would be reasonable to suppose it would perform well in external validation studies. However, this was not the rule. SAPS III general equations discriminated very well in almost all studies, but calibration tests suggested significant departures from perfect calibration in most of them, especially in large studies (as should be expected by the extensive use of the $\mathrm{H}$-L, $C$ - and $H$-statistics). SAPS III customized equations have not delivered a better performance than the general equation in most of the studies. However, local customization has provided non-statistically significant departures from perfect calibration for SAPS III in all studies that performed it.

Calibration refers to the agreement between observed and predicted risks. A non-statistically significant departure from perfect calibration, that is, a $P$-value higher than 0.05 , in an external validation study means the prognostic model predicts mortality risk adequately in this population. Therefore, this population and the one in which the original model was developed are similar. A series of reasons can be responsible for significant departures from perfect calibration. Among these are sampling bias, variations in case-mix and temporal bias (either in the process of care or in the case-mix).

SAPS III original cohort included patients with a median age of 64 years; $39.4 \%$ of the patients were female and $51.5 \%$ of them were surgical (elective and emergency). Differences in case-mix were important in the included studies. Mean or median age varied from 46.0 to 73.4 years-old; female patients varied from 34.5 to $66.3 \%$; and the proportion of surgical patients varied from 0 to $100 \%$. Interestingly, if we choose two studies with similar populations according to these three variables - studies performed by Metnitz [36] and by Strand [37] - we observe that a significant departure from perfect calibration was found in the former, but not in the latter. Even more interestingly, SAPS III had non-significant departures from perfect calibration in studies that included higher proportions of surgical patients $[15,19,20,34]$ than the original SAPS III study, but that also happened in a study that included only medical patients [29]. Of course, not only these three variables explain similar or different case-mixes. Poor SAPS III performance may also be due to differences in healthcare provisions [43] and end-of-life policies [44], for example.

Another point that deserves attention is the application of a prognostic model in a population admitted to ICU because of a specific diagnosis. SAPS III had a nonsignificant departure from perfect calibration and still had very good discrimination in a common ICU syndrome - AKI - when calculated with data collected on the diagnosis day, on the day of nephrology consultation [21] or at the start of renal replacement therapy [18,31]. On the other hand, SAPS III was statistically significantly mis-calibrated in an assessment of septic shock patients, although it discriminated very well [30]. Two studies that included patients with a specific diagnosis at admission, however, showed very poor performance of SAPS III. In transplant patients, SAPS III was statistically significantly mis-calibrated, had only moderate discrimination and underestimated hospital mortality [24]. In acute coronary syndrome patients, SAPS III also was statistically significantly mis-calibrated and overestimated hospital mortality, although it discriminated well in this population [23]. These findings are not unexpected. General prognostic models usually do not perform well in specific subgroups of patients because they may be under-represented in the developed cohort [6]. For some specific diagnoses, a specific prognostic model may be an attractive alternative $[23,45]$.

Temporal bias is another problem frequently reported as a reason for significant differences from perfect calibration. 
Table 3 Performance of general and customized SAPS III equations for major geographic regions

\begin{tabular}{|c|c|c|c|c|c|}
\hline Study & $\begin{array}{l}\text { Calibration for } \\
\text { general SAPS III }\end{array}$ & $\begin{array}{l}\text { Calibration for } \\
\text { customized SAPS III }\end{array}$ & aROC $(95 \% \mathrm{Cl})$ & $\begin{array}{l}\text { SMR }(95 \% \mathrm{Cl}) \text { for } \\
\text { general SAPS III }\end{array}$ & $\begin{array}{l}\text { SMR }(95 \% \text { Cl) for } \\
\text { customized SAPS III }\end{array}$ \\
\hline \multicolumn{6}{|c|}{ Central and South America } \\
\hline Soares, 2006 [15] & $C: 13.637(P=0.092)$ & $C: 9.132(P=0.331)$ & 0.87 (0.85 to 0.90$)$ & 1.19 (1.04 to 1.37$)$ & 0.95 (0.84 to 1.07$)$ \\
\hline Serrato, 2007 [16] & $C: 6.64(P>0.1)$ & NR & 0.86 (0.825 to 0.895$)$ & 0.81 & NR \\
\hline \multirow[t]{2}{*}{ Alves, 2009 [17] } & $H: 16.42(P=0.037)$ & $H: 16.66(P=0.034)$ & 0.881 (0.843 to 0.913 ) & $1.10(0.90$ to 1.33$)$ & 0.86 (0.70 to 1.04$)$ \\
\hline & $C: 17.57(P=0.025)$ & $C: 15.95(P=0.047)$ & & & \\
\hline Maccariello, 2010 [18] & $C: 10.16(P=0.254)$ & $C: 9.33(P=0.315)$ & 0.82 (0.76 to 0.88$)$ & $1.26(1.10$ to 1.46$)$ & 1.04 (0.92 to 1.18$)$ \\
\hline Silva Junior, 2010 [19] & $C: 10.47(P=0.234)$ & NR & 0.86 (0.83 to 0.88$)$ & 1.04 (1.03 to 1.07$)$ & NR \\
\hline Soares, 2010 [20] & $C: 15.804(P=0.045)$ & $C: 12.607(P=0.126)$ & 0.84 (0.81 to 0.87$)$ & 1.29 (1.09 to 1.53$)$ & 1.02 (0.87 to 1.19$)$ \\
\hline \multirow[t]{2}{*}{ Costa e Silva, 2011 [21] } & $H(D D): 6.86(P=0.551)$ & $H(\mathrm{DD}): 6.33(P=0.610)$ & DD: 0.73 (0.67 to 0.78 ) & DD: 1.35 (1.07 to 1.63$)$ & DD: 1.09 (0.83 to 1.35$)$ \\
\hline & $H(\mathrm{NCD}): 10.47(P=0.163)$ & $H(\mathrm{NCD}): 13.22(P=0.113)$ & NCD: 0.80 (0.73 to 0.86$)$ & NCD: 1.15 (0.75 to 1.55$)$ & NCD: 1.00 (0.61 to 1.39$)$ \\
\hline Nassar Junior, 2012 [22] & $C: 226.6(P<0.001)$ & NR & 0.855 (0.846 to 0.864$)$ & $0.46(0.37$ to 0.54$)$ & NR \\
\hline Nassar Junior, 2013 [23] & $C: 51.8(P<0.001)$ & NR & 0.804 (0.779 to 0.828) & 0.31 (0.11 to 0.50$)$ & NR \\
\hline \multirow[t]{2}{*}{ De Oliveira, 2013 [24] } & H: $59.41(P<0.001)$ & C: $123.49(P<0.001)$ & 0.696 (0.607 to 0.786$)$ & 1.94 (1.38 to 2.64$)$ & 1.88 (1.34 to 2.56$)$ \\
\hline & $C: 155.57(P<0.001)$ & $H: 45.6(P<0.001)$ & & & \\
\hline \multicolumn{6}{|l|}{ North America } \\
\hline Keegan, 2012 [25] & $C: 36.6(P<0.05)$ & NR & 0.801 (0.785 to 0.816$)$ & 0.66 (0.69 to 0.75$)$ & NR \\
\hline \multicolumn{6}{|l|}{ Australasia } \\
\hline \multirow[t]{2}{*}{ Duke, 2008 [26] } & $H: 36.15(P=0.009)$ & $H: 27.37(P=0,06)$ & 0.88 (0.85 to 0.90$)$ & 0.84 (0.724 to 0.969$)$ & $0.92(0.80$ to 1.06$)$ \\
\hline & $C: ?(P=0.019)$ & & & & \\
\hline Tsai, 2008 [31] & $H: 5.445(P=0.71)$ & NR & 0.73 & NR & NR \\
\hline \multirow[t]{2}{*}{ Khwannimit, 2010 [27] } & $H: 106.7(P<0.001)$ & $H: 98.2(P<0.001)$ & 0.933 (0.921 to 0.944$)$ & 0.86 (0.79 to 0.93$)$ & 0.92 (0.85 to 0.99$)$ \\
\hline & C: $101.2(P<0.001)$ & $C: 96.2(P<0.001)$ & & & \\
\hline \multirow[t]{2}{*}{ Khwannimit, 2011 [28] } & $H: 101.6(P<0.001)$ & $H: 79.9(P<0.001)$ & 0.916 (0.902 to 0.929$)$ & 0.81 (0.74 to 0.88$)$ & 0.88 (0.80 to 0.96$)$ \\
\hline & $C: 176.3(P<0.001)$ & $C: 170(P<0.001)$ & & & \\
\hline Lim, 2011 [32] & $C: 3.174(P=0.923)$ & $C: 3.286(P=0.915)$ & 0.78 (0.75 to 0.81$)$ & 0.72 (0.62 to 0.83$)$ & 0.78 (0.67 to 0.89$)$ \\
\hline Juneja, 2012 [29] & HL(?): $13.12(P=0.108)$ & NR & 0.901 (0.871 to 0.932 ) & 0.763 (0.628 to 0.918$)$ & NR \\
\hline \multirow[t]{2}{*}{ Khwannimit, 2013 [30] } & $H: 39.4(P<0.001)$ & NR & 0.817 (0.790 to 0.845$)$ & 0.97 (0.89 to 1.06$)$ & NR \\
\hline & $C: 49.6(P<0.001)$ & & & & \\
\hline \multirow[t]{2}{*}{ Lim, 2013 [33] } & $H: 123.06(P<0.001)$ & $H: 73.53(P<0.001)$ & 0.829 (0.82 to 0.86$)$ & 0.72 (0.65 to 0.78$)$ & 0.78 (0.71 to 0.85$)$ \\
\hline & $C: 118.45(P<0.001)$ & $C: 70.52(P<0.001)$ & & & \\
\hline \multicolumn{6}{|c|}{ Central and Western Europe } \\
\hline Ledoux, 2008 [34] & $C: 16.59(P=0.035)$ & $C: 8.30(P=0.405)$ & 0.85 (0.82 to 0.89$)$ & 0.82 (0.70 to 0.93 ) & 0.96 (0.84 to 1.08$)$ \\
\hline \multirow[t]{2}{*}{ Sakr, 2008 [35] } & $H: 211.84(P<0.001)$ & $H: 177.37(P<0.001)$ & 0.84 (0.81 to 0.88 ) & NR & NR \\
\hline & $C: 208.49(P<0.001)$ & C: $126.79(P<0.001)$ & & & \\
\hline \multirow[t]{2}{*}{ Metnitz, 2009 [36] } & $H: 100.18(P<0.001)$ & $H: 51.56(P<0.001)$ & 0.82 & 0.79 (0.74 to 0.85$)$ & 0.86 (0.80 to 0.92$)$ \\
\hline & C: $90.29(P<0.001)$ & $C: 45.61(P<0.001)$ & & & \\
\hline \multicolumn{6}{|l|}{ Northern Europe } \\
\hline Strand, 2009 [37] & $C: 17.40(P=0.066)$ & $C: 18.25(P=0.051)$ & 0.81 (0.79 to 0.93 ) & 0.71 (0.65 to 0.78 ) & 0.74 (0.68 to 0.81$)$ \\
\hline Christensen, 2011 [38] & $\mathrm{HL}(?): 9.23(P=0.51)$ & NR & 0.69 (0.63 to 0.75$)$ & NR & NR \\
\hline
\end{tabular}


Table 3 Performance of general and customized SAPS III equations for major geographic regions (Continued)

\begin{tabular}{|c|c|c|c|c|c|}
\hline \multicolumn{6}{|c|}{ Southern Europe and Mediterranean countries } \\
\hline \multirow[t]{2}{*}{ Capuzzo, 2009 [39] } & $H: 23.36(P=0.002)$ & $H: 25.73(P=0.001)$ & 0.835 (0.794 to 0.876$)$ & 0.83 (0.77 to 0.89$)$ & 0.81 (0.75 to 0.87 ) \\
\hline & $C: 22.47(P=0.004)$ & $C: 26.19(P=0.001)$ & & & \\
\hline Mbongo, 2009 [40] & $C: 8.57(P=0.38)$ & $C: 7.5(P=0.48)$ & 0.917 (0.880 to 0.954) & 0.71 (0.56 to 0.90$)$ & 0.69 (0.55 to 0.87 ) \\
\hline Poole, 2009 [41] & $U^{\mathrm{a}}: 2,035,9(P<0.001)$ & $U^{\mathrm{a}}: 1,929.2(P<0.001)$ & 0.855 (0.851 to 0.860$)$ & $0.73(0.72$ to 0.75$)$ & 0.73 (0.72 to 0.75$)$ \\
\hline López-Caler, 2013 [42] & HL(?): $20.05(P<0.05)$ & 0.855 (0.851 to 0.860$)$ & 0.845 (0.821 to 0.869$)$ & 0.89 (0.80 to 0.98$)$ & 0.86 (0.77 to 0.95$)$ \\
\hline
\end{tabular}

aROC, area under the receiver operator characteristic curve; SAP, simplified acute physiology score; SMR, standardized mortality ratios; $H$, Hosmer-Lemeshow H-statistic; C, Hosmer-Lemeshow C-statistic; HL(?), Hosmer-Lemeshow statistic unspecified; NR, not reported; DD, acute kidney injury diagnosis-day; NCD, day of nephrology consultation. ${ }^{a} \mathrm{U}$ statistics quantifies the difference from the null hypothesis, that is, a good fit of the model in the studied population when Cox calibration test is used.

SAPS III was developed with 2002 data. It is possible that changes in case-mix or clinical practice over time may limit the application of a prognostic model. Analyzing study periods in Table 1 and calibrations in Table 3, it is not possible to conclude that studies that collected data in a specific period of time also found a better SAPS III performance.

A large database of patients from seven different major geographic regions allowed SAPS III customized equations for each region. In the original study, these customized equations were not statistically significantly different from perfect calibration [6]. Among included studies that also assessed customized equations, there were only three in which the customized equation did not show a statistically significant mis-calibration in a population in which the general equation also showed the same findings. Despite being developed to fit better, these equations may not be representative of populations from a specific region. For example, SAPS III included 1,756 Australasian patients, but these patients were only from Australia, Hong Kong and India. Khwannimit et al. performed their studies in a Thai population, and the Australasian SAPS III was also statistically mis-calibrated $[27,28,30]$. Similar findings were identified by Lim et al. in a broad South Korean population [33].

A better explanation for SAPS III departures from perfect calibration may be the limitations of the statistics methods used to evaluate performance. Calibration statistics (specially H-L goodness-of-fit statistics) present several problems, mainly the fact that they are very sensitive to larger sample sizes because larger studies have more power to detect departures from perfect calibration $[10,46]$. Thus, even small deviations from the perfect calibration in larger studies may be associated with a $P$-value $>0.05$. An interesting study compared the performance of SAPS II, APACHE II and the mortality predict model II (MPM-II) in a Dutch population of 42,139 patients. All models showed statistically significant departures from perfect calibration, both on the $\mathrm{H}-\mathrm{L}$ and on the Cox calibration test. However, when prognostic models were assessed in subsamples drawn from the database, performance was better. There was a tendency to reject the model when these samples increased [11]. Our review suggested a correlation between larger studies and higher values in $\mathrm{H}-\mathrm{L}$ statistics, as we should expect.

Although neither the SAPS III general equation nor its customized equations for major geographic areas did not show statistical goodness-of-fit in most studies, all studies that performed a customization, developed local models that did not show significant departures from perfect calibration and had a very good discrimination. The development of country-specific equations was previewed in the original SAPS III description [6,36]. These findings highlight the value and weight of variables included in SAPS III, as first-line customizations provided valid models in all studies. Models with only a few parameters, such as SAPS III, are quite stable and can easily be turned into a statistically calibrated model with a first-level customization [47]. However, only two studies that developed local models were multicenter. Thus, one may argue against considering that a model is valid for a country or region if it was customized only with data from a single ICU.

Discrimination refers to how well the model discriminates between an individual who will live and one who will die. Good, very good or excellent discrimination was found in almost all studies. Only two studies had an aROC $<0.7[24,38]$. Both were single center and one of them was performed in transplant patients [24], a very specific population. We believe this is a reassuring finding for those using SAPS III for clinical or research purposes in general populations of critically ill patients.

In addition to limitations of the included studies, one possible limitation of this review is how databases were searched. Although we did not restrict our search to English language articles, there were language restrictions that may have caused us to miss some studies. Also, we performed searches on databases that include only studies from Latin America (Lilacs), and from Latin America, Portugal, Spain and South Africa (Scielo). That may have been responsible for the high number of Latin American and Spanish studies analyzed, which encompassed almost half of the included studies. However, all studies, except for two $[16,17]$, were also indexed on Medline. One of them was retrieved from Scielo [17] and the other from Google Scholar [16]. 


\section{Conclusions}

Although SAPS III was the first intensive care prognostic model developed with patient data from different regions of the world, its performance in external validation studies was far from perfect. Even its major geographic customized equations showed significant departures from perfect calibration. Local and country customizations, on the other hand, improved its performance. Discrimination was almost always very good or excellent. We believe that SAPS III is a reliable, simple and easy prognostic model to be used in clinical practice, but it should be customized before routine application in local settings. This statement is possibly (probably) true for all general outcome prediction models. In addition to that, it seems that SAPS III should not be used to assess patients admitted with specific diagnoses.

\section{Key messages}

- SAPS III showed significant departure from perfect calibration in most studies

- There was a positive correlation between larger samples and higher H-L values for SAPS III. As calibration statistics are very sensitive to sample sizes, this is probably the best explanation for the significant departures from perfect calibration found in the larger studies

- SAPS III discrimination is very good

- First-level customization improved SAPS III performance in all studies in which it was accomplished, although most of them were single-center studies

- SAPS III is a reliable prognostic model to be used in clinical practice, but it should be customized before routine application in local settings.

\footnotetext{
Abbreviations

AKI: acute kidney injury; aROC: area under the receiver operator characteristic curve; H-L: Hosmer-Lemeshow; PRISMA: preferred reporting items for systematic reviews and meta-analyses; SAPS: simplified acute physiology score; SMR: standardized mortality ratio.
}

\section{Competing interests}

The authors declare that they have no competing interests.

\section{Authors' contributions}

APNJ conceived of this study, carried out the search queries, reviewed the articles, assessed their quality, extracted the data and drafted the manuscript. LMSM carried out the search queries, reviewed the articles, extracted the data and helped to draft the manuscript. RM participated in the design and coordination of the study and helped to draft the manuscript. All authors read and approved the manuscript.

\section{Acknowledgements}

We would like to thank Barbara Weninger for language revision of the manuscript.

\section{Author details}

${ }^{1}$ Anesthesiology Department, Hospital das Clinicas SP-FMUSP, Av. Dr. Enéas de Carvalho Aguiar, 255, Cerqueira César, São Paulo, SP 05403-000, Brazil. Unidade de Cuidados Intensivos Neurocríticos, Hospital de São José, Centro
Hospitalar de Lisboa Central, Faculdade de Ciências Médicas de Lisboa, Universidade Nova de Lisboa, EPE, 1169-050 Lisbon, Portugal.

Received: 10 January 2014 Accepted: 21 May 2014

Published: 6 June 2014

\section{References}

1. Vincent $J \mathrm{~L}$, Moreno R: Clinical review: scoring systems in the critically ill. Crit Care 2010, 14:207.

2. Knaus WA, Draper EA, Wagner DP, Zimmerman JE: APACHE II: a severity of disease classification system. Crit Care Med 1985, 13:818-829.

3. Le Gall JR, Lemeshow S, Saulnier F: A new Simplified Acute Physiology Score (SAPS II) based on a European/North American multicenter study. JAMA 1993, 270:2957-2963.

4. Rhodes A, Moreno RP, Azoulay E, Capuzzo M, Chiche JD, Eddleston J, Endacott R, Ferdinande P, Flaatten H, Guidet B, Kuhlen R, León-Gil C, Martin Delgado MC, Metnitz PG, Soares M, Sprung CL, Timsit JF, Valentin A, Task Force on Safety and Quality of European Society of Intensive Care Medicine (ESICM): Prospectively defined indicators to improve the safety and quality of care for critically ill patients: a report from the Task Force on Safety and Quality of the European Society of Intensive Care Medicine (ESICM). Intensive Care Med 2012, 38:598-605.

5. Metnitz PG, Moreno RP, Almeida E, Jordan B, Bauer P, Campos RA, lapichino G, Edbrooke D, Capuzzo M, Le Gall JR: SAPS 3-From evaluation of the patient to evaluation of the intensive care unit. Part 1: Objectives, methods and cohort description. Intensive Care Med 2005, 31:1336-1344.

6. Moreno RP, Metnitz PG, Almeida E, Jordan B, Bauer P, Campos RA, lapichino G, Edbrooke D, Capuzzo M, Le Gall JR: SAPS 3-From evaluation of the patient to evaluation of the intensive care unit. Part 2: Development of a prognostic model for hospital mortality at ICU admission. Intensive Care Med 2005, 31:1345-1355.

7. Liberati A, Altman DG, Tetzlaff J, Mulrow C, Gotzsche PC, loannidis JP, Clarke M, Devereaux PJ, Kleijnen J, Moher D: The PRISMA statement for reporting systematic reviews and meta-analyses of studies that evaluate healthcare interventions: explanation and elaboration. BMJ 2009, 339:b2700.

8. Hayden JA, Cote P, Bombardier C: Evaluation of the quality of prognosis studies in systematic reviews. Ann Intern Med 2006, 144:427-437.

9. Moreno R, Apolone G: Impact of different customization strategies in the performance of a general severity score. Crit Care Med 1997, 25:2001-2008.

10. Kramer AA, Zimmerman JE: Assessing the calibration of mortality benchmarks in critical care: The Hosmer-Lemeshow test revisited. Crit Care Med 2007, 35:2052-2056.

11. Peek N, Arts DG, Bosman RJ, van der Voort PH, de Keizer NF: External validation of prognostic models for critically ill patients required substantial sample sizes. J Clin Epidemiol 2007, 60:491-501.

12. Surbatovic M, Radakovic S, Jevtic M, Filipovic N, Romic P, Popovic N, Jevdjic J, Grujic K, Djordjevic D: Predictive value of serum bicarbonate, arterial base deficit/excess and SAPS III score in critically ill patients. Gen Physiol Biophys 2009, 28 Spec No:271-276.

13. Salciccioli JD, Cristia C, Chase M, Giberson T, Graver A, Gautam S, Cocchi MN, Donnino MW: Performance of SAPS II and SAPS III scores in post-cardiac arrest. Minerva Anestesiol 2012, 78:1341-1347.

14. Timmers T, Verhofstad M, Moons K, Leenen L: Validation of six mortality prediction systems for ICU surgical populations. Netherlands J Crit Care 2011, 15:118-130.

15. Soares M, Salluh Jl: Validation of the SAPS 3 admission prognostic model in patients with cancer in need of intensive care. Intensive Care Med 2006, 32:1839-1844.

16. Serrato CAA, Díaz UWC, Unzueta AS: Comparación del rendimiento de 2 modelos predictivos de mortalidad: SAPS 3 vs APACHE II, en una unidad de terapia intensiva mexicana. Rev Asoc Mex Med Crit y Ter Int 2007, 21:119-124.

17. Alves CJ, Franco GPP, Nakata CT, Costa GLG, Costa GLG, Genaro MSA, Agostini G, Luz JL, Leite MFM: Avaliação de índices prognósticos para pacientes idosos admitidos em unidades de terapia intensiva. Revista Brasileira de Terapia Intensiva 2009, 21:1-8.

18. Maccariello E, Valente $C$, Nogueira L, Bonomo H, Ismael M, Machado JE, Baldotto F, Godinho M, Valenca R, Rocha E, Soares M: SAPS 3 scores at the start of renal replacement therapy predict mortality in critically ill patients with acute kidney injury. Kidney Int 2010, 77:51-56. 
19. Silva Junior JM, Malbouisson LM, Nuevo HL, Barbosa LG, Marubayashi LY, Teixeira IC, Nassar Junior AP, Carmona MJ, Silva IF, Auler Junior JO, Rezende E: Applicability of the simplified acute physiology score (SAPS 3) in Brazilian hospitals. Rev Bras Anestesiol 2010, 60:20-31.

20. Soares M, Silva UV, Teles JM, Silva E, Caruso P, Lobo SM, Dal Pizzol F, Azevedo $L P$, de Carvalho FB, Salluh Jl: Validation of four prognostic scores in patients with cancer admitted to Brazilian intensive care units: results from a prospective multicenter study. Intensive Care Med 2010, 36:1188-1195.

21. Silva VT C e, de Castro I, Liano F, Muriel A, Rodriguez-Palomares JR, Yu L: Performance of the third-generation models of severity scoring systems (APACHE IV, SAPS 3 and MPM-III) in acute kidney injury critically ill patients. Nephrol Dial Transplant 2011, 26:3894-3901.

22. Nassar AP Jr, Mocelin AO, Nunes AL, Giannini FP, Brauer L, Andrade FM, Dias CA: Caution when using prognostic models: a prospective comparison of 3 recent prognostic models. J Crit Care 2012, 27:423. e421-427.

23. Nassar Junior AP, Mocelin AO, Andrade FM, Brauer L, Giannini FP, Nunes ALB, Dias CA: SAPS 3, APACHE IV or GRACE: which score to choose for acute coronary syndrome patients in intensive care units? Sao Paulo Med J 2013, 131:173-178.

24. Oliveira VM, Brauner JS, Rodrigues Filho E, Susin RGA, Draghetti V, Bolzan ST, Vieira SRR: Is SAPS 3 better than APACHE II at predicting mortality in critically ill transplant patients? Clinics 2013, 68:153-158.

25. Keegan MT, Gajic O, Afessa B: Comparison of APACHE III, APACHE IV, SAPS 3 , and MPMOIII and influence of resuscitation status on model performance. Chest 2012, 142:851-858.

26. Duke GJ, Piercy M, DiGiantomasso D, Green JV: Comparison of intensive care outcome prediction models based on admission scores with those based on 24-hour data. Anaesth Intensive Care 2008, 36:845-849.

27. Khwannimit B, Bhurayanontachai R: The performance and customization of SAPS 3 admission score in a Thai medical intensive care unit. Intensive Care Med 2010, 36:342-346.

28. Khwannimit B, Bhurayanontachai R: A comparison of the performance of Simplified Acute Physiology Score 3 with old standard severity scores and customized scores in a mixed medical-coronary care unit. Minerva Anestesiol 2011, 77:305-312.

29. Juneja $D$, Singh $O$, Nasa $P$, Dang R: Comparison of newer scoring systems with the conventional scoring systems in general intensive care population. Minerva Anestesiol 2012, 78:194-200.

30. Khwannimit B, Bhurayanontachai R: Validation of predisposition, infection, response and organ dysfunction score compared with standard severity scores in predicting hospital outcome in septic shock patients. Minerva Anestesiol 2013, 79:257-263.

31. Tsai CW, Lin YF, Wu VC, Chu TS, Chen YM, Hu FC, Wu KD, Ko WJ: SAPS 3 at dialysis commencement is predictive of hospital mortality in patients supported by extracorporeal membrane oxygenation and acute dialysis. Eur J Cardiothorac Surg 2008, 34:1158-1164.

32. Lim SY, Ham CR, Park SY, Kim S, Park MR, Jeon K, Um SW, Chung MP, Kim H, Kwon OJ, Suh GY: Validation of the Simplified Acute Physiology Score 3 scoring system in a Korean intensive care unit. Yonsei Med J 2011, 52:59-64.

33. Lim SY, Koh SO, Jeon K, Na S, Lim CM, Choi WI, Lee YJ, Kim SC, Chon GR, Kim JH, Kim JY, Lim J, Rhee CK, Park S, Kim HC, Lee JH, Lee JH, Park J, Koh Y, Suh GY, Validation of Simplified acute physiology score 3 in Korean Intensive care unit (VSKI) study group; Korean Study group on Respiratory Failure (KOSREF): Validation of SAPS3 admission score and its customization for use in Korean intensive care unit patients: a prospective multicentre study. Respirology 2013, 18:989-995.

34. Ledoux D, Canivet JL, Preiser JC, Lefrancq J, Damas P: SAPS 3 admission score: an external validation in a general intensive care population. Intensive Care Med 2008, 34:1873-1877.

35. Sakr Y, Krauss C, Amaral AC, Rea-Neto A, Specht M, Reinhart K, Marx G: Comparison of the performance of SAPS II, SAPS 3, APACHE II, and their customized prognostic models in a surgical intensive care unit. $\mathrm{Br} J$ Anaesth 2008, 101:798-803.

36. Metnitz B, Schaden E, Moreno R, Le Gall JR, Bauer P, Metnitz PG: Austrian validation and customization of the SAPS 3 Admission Score. Intensive Care Med 2009, 35:616-622

37. Strand K, Soreide E, Aardal S, Flaatten H: A comparison of SAPS II and SAPS 3 in a Norwegian intensive care unit population. Acta Anaesthesiol Scand 2009, 53:595-600.

38. Christensen $\mathrm{S}$, Johansen MB, Christiansen CF, Jensen $\mathrm{R}$, Lemeshow $\mathrm{S}$ : Comparison of Charlson comorbidity index with SAPS and APACHE scores for prediction of mortality following intensive care. Clin Epidemiol 2011, 3:203-211.

39. Capuzzo M, Scaramuzza A, Vaccarini B, Gilli G, Zannoli S, Farabegoli L, Felisatti G, Davanzo E, Alvisi R: Validation of SAPS 3 Admission Score and comparison with SAPS II. Acta Anaesthesiol Scand 2009, 53:589-594.

40. Mbongo CL, Monedero P, Guillen-Grima F, Yepes MJ, Vives M, Echarri G: Performance of SAPS3, compared with APACHE II and SOFA, to predict hospital mortality in a general ICU in Southern Europe. Eur J Anaesthesiol 2009, 26:940-945.

41. Poole D, Rossi C, Anghileri A, Giardino M, Latronico N, Radrizzani D, Langer M, Bertolini G: External validation of the Simplified Acute Physiology Score (SAPS) 3 in a cohort of 28,357 patients from 147 Italian intensive care units. Intensive Care Med 2009, 35:1916-1924.

42. Lopez-Caler C, Garcia-Delgado M, Carpio-Sanz J, Alvarez-Rodriguez J, Aguilar-Alonso E, Castillo-Lorente E, Barrueco-Francioni JE, Rivera-Fernandez R: External validation of the Simplified Acute Physiology Score (SAPS) 3 in Spain. Med Intensiva 2013, 38:288-296.

43. Eachempati SR, Hydo LJ, Barie PS: The effect of an intermediate care unit on the demographics and outcomes of a surgical intensive care unit population. Arch Surg 2004, 139:315-319.

44. Yaguchi A, Truog RD, Curtis JR, Luce JM, Levy MM, Melot C, Vincent JL: International differences in end-of-life attitudes in the intensive care unit: results of a survey. Arch Intern Med 2005, 165:1970-1975.

45. Amalio SM, Macedo MA, Carvalho SM, Moreno RP: Mortality assessment in patients with severe acute pancreatitis: a comparative study of specific and general severity indices. Rev Bras Ter Intensiva 2012, 24:246-251.

46. Bertolini G, D'Amico R, Nardi D, Tinazzi A, Apolone G: One model, several results: the paradox of the Hosmer-Lemeshow goodness-of-fit test for the logistic regression model. J Epidemiol Biostat 2000, 5:251-253.

47. van Houwelingen $\mathrm{HC}$ : Validation, calibration, revision and combination of prognostic survival models. Stat Med 2000, 19:3401-3415.

doi: $10.1186 /$ cc13911

Cite this article as: Nassar et al:: Evaluation of simplified acute physiology score 3 performance: a systematic review of external validation studies. Critical Care 2014 18:R117.

\section{Submit your next manuscript to BioMed Central and take full advantage of:}

- Convenient online submission

- Thorough peer review

- No space constraints or color figure charges

- Immediate publication on acceptance

- Inclusion in PubMed, CAS, Scopus and Google Scholar

- Research which is freely available for redistribution 